\title{
DETECCIÓN TEMPRANA: ¿EL PAPANICOLAOU ES SIEMPRE LA MEJOR OPCIÓN?
}

\author{
EARLY DETECTION: THE PAP SMEAR IS ALWAYS THE BEST OPTION?
}

Franshesca L. Sedano-Chiroque ${ }^{1, a}$

\begin{abstract}
Sr. Editor
El cáncer de cuello uterino (CACU) en el Perú, presenta una tasa de incidencia y mortalidad de 32,7 y 12,0 por 100000 habitantes respectivamente ${ }^{(1)}$; y esta ocupa el cuarto lugar como una de las neoplasias más frecuentes con 569847 casos reportados en el año 2018 a nivel mundial(2). Estas estadísticas, ameritan evaluar qué acciones sanitarias pueden garantizar la detección temprana de esta enfermedad.

De acuerdo con el Plan Nacional para la Prevención y Control del Cáncer de Cuello Uterino ${ }^{(3)}$, el tamizaje de esta patología en el Perú establece realizar la prueba de la inspección visual con ácido acético (IVAA) desde los 30 a 49 años, mientras que la citología convencional (PAP) desde los 50 a los 64 años; estos representan intervalos de años en los que no se puede evaluar de manera retrospectiva las etapas tempranas del cáncer, sobre todo en mujeres que no han recibido inmunización previamente o que tienen una vida sexual activa antes de los 15 años.
\end{abstract}

En el Perú, la prueba de Papanicolaou (PAP), si bien es cierto es accesible en los tres niveles de atención, proporciona baja sensibilidad y limitada reproducibilidad ${ }^{(3)}$. Esto podría suponer falsos negativos que, a su vez generaría una detección tardía de cáncer de cérvix, produciendo a la larga mayores costes en el tratamiento y bajo control de la enfermedad, sin considerar aún las consecuencias.

Por otro lado, existen otros tipos de pruebas de detección, como son las moleculares y genéticas con características establecidas( ${ }^{(4)}$ (ver Tabla 1). Sin embargo, en esta ocasión se plantea la evaluación e implementación de la Citología de Base Líquida (LBC por sus siglas en inglés), también conocida como Prueba Citológica ThinPrep (TCT).

La LBC es un procedimiento que no requiere de un extendido inicial, por lo general se extrae la muestra con un cepillo y se deposita en un líquido fijador, este preparado se debe centrifugar para así detectar lesiones escamosas intraepiteliales, y la ventaja es que puede usarse repetidas veces a diferencia de otras pruebas.

Si bien es cierto, en algunos estudios se dice que la sensibilidad y valores de predicción son similares al PAP(5), otras publicaciones demuestran una sensibilidad que va desde $79,1 \%$ a $90 \%$, dejando atrás a la inspección visual con ácido acético (30 a 87\%), Lugol (87,2\%) y citología convencional (32,4 a 90\%); técnicas de tamizaje comúnmente empleadas en países subdesarrollados ${ }^{(4)}$.

Un estudio realizado por Liu Y. et al. ${ }^{(6)}$, en muestras obtenidas de 420 mujeres, sugiere que la mejor manera de garantizar una alta sensibilidad en el diagnóstico es optar por realizar la LBC combinada con la prueba de detección de ADN del Virus del Papiloma Humano.

De esta manera, podemos concluir que para detectar tempranamente el cáncer de cérvix y basándose en la evidencia científica, la prueba de LBC resulta una alternativa factible y eficaz para nuestra población en el Perú. Por lo que, en mejora de las políticas públicas, se podrían establecer alianzas con empresas especializadas en este procedimiento, a fin de reducir sus costos de implementación, garantizando a la larga, mayores estándares de calidad respecto a prevención.

1 Universidad César Vallejo, Piura-Perú.

Estudiante de medicina.

Citar como: Franshesca L. Sedano-Chiroque. Detección temprana: ¿El papanicolaou es siempre la mejor opción?. Rev. Fac. Med. Hum. Abril 2020; 20(2):343-344. DOI 10.25176/RFMH.v20i2.2903 
Tabla 1. Resumen de pruebas de tamizaje para cáncer cervicouterino y virus del papiloma humano.

\begin{tabular}{|c|c|c|c|c|}
\hline Prueba & Detecta & Uso & Sensibilidad & Especificidad \\
\hline $\begin{array}{l}\text { Citología convencional/ } \\
\text { Papanicolaou }\end{array}$ & Células anormales & $\begin{array}{l}\text { Posibles lesiones } \\
\text { cervicales }\end{array}$ & $32,4 \%$ a $90 \%$ & $94 \%$ \\
\hline Citología a base líquida & Células anormales & $\begin{array}{l}\text { Posibles lesiones } \\
\text { cervicales }\end{array}$ & $79,1 \%$ a $90,4 \%$ & NA \\
\hline $\begin{array}{l}\text { Inspección visual ácido } \\
\text { acético }\end{array}$ & $\begin{array}{c}\text { Lesiones cervicales } \\
\text { visibles }\end{array}$ & $\begin{array}{l}\text { Posibles lesiones } \\
\text { cervicales }\end{array}$ & $30 \%$ a $87 \%$ & $86 \%$ a $100 \%$ \\
\hline Inspección visual lugol & $\begin{array}{c}\text { Lesiones cervicales } \\
\text { visibles }\end{array}$ & $\begin{array}{l}\text { Posibles lesiones } \\
\text { cervicales }\end{array}$ & $87,2 \%$ & $84,7 \%$ \\
\hline Colposcopia & Neoplasia cervical & $\begin{array}{l}\text { Lesiones } \\
\text { cervicales }\end{array}$ & $83 \%$ & $86 \%$ \\
\hline Híbridos II & VPH & $\begin{array}{l}\text { Detección de VPH } \\
\text { de alto y bajo }\end{array}$ & $96 \%$ & $66,7 \%$ \\
\hline Híbridos III & VPH & riesgo (13 tipos) & $87,7 \%$ a $96,9 \%$ & $90,6 \%$ \\
\hline PCR & VPH & $\begin{array}{c}\text { Detección de VPH } \\
\text { de alto y bajo riesgo } \\
\text { (27 tipos) }\end{array}$ & $83,9 \%$ a $100 \%$ & $64,1 \%$ a $95,1 \%$ \\
\hline
\end{tabular}

Fuente: Samperio Calderón JE, Salazar Campos A. Eficacia de las pruebas diagnósticas del cáncer cervicouterino y Virus del Papiloma Humano. JONNPR. 2019;4(5):551-66. DOI: 10.19230/jonnpr.2953

Contribuciones de autoría: La autora realizó la generación, recolección de información, redacción y versión final del artículo original.

Financiamiento: Autofinanciado.

Correspondencia: Franshesca L. Sedano-Chiroque.

Dirección: Av. Chulucanas s/n, Piura 20001-Perú.

Teléfono: 998040757

Correo: franshesca.sedano@gmail.com
Conflicto de interés: La autora declara no tener conflictos de interés en la publicación de este artículo.

Recibido: 14 de marzo 2020

Aprobado: 24 de marzo 2020

\section{REFERENCIAS BIBLIOGRÁFICAS}

1.56th DIRECTING COUNCIL: 70th SESSION OF THE REGIONAL COMMITTEE OF WHOFORTHEAMERICAS.Washington D.C;23-27September 2018. Washington: Pan American Health Organization; 2018. Avaliable from: https://www.paho. org/hq/index.php?option=com docman\&view=download\&category slug=56-directing-council-english-9964\&alias=45803-cd56-9-e-poa-cervicalcancer-803\&ltemid=270\&lang=es

2. Ferlay J, Soerjomataram I, Ervik M, Dikshit R, Eser S, Mathers C, et al GLOBOCAN 2012 v1.0, Estimated Cancer Incidence, Mortality and Prevalence Worldwide: IARC Cancer Base No. 11 [Internet]. Lyon, France: International Agency for Research on Cancer; 2013 [cited 2020 Feb 20]. Available from: http://globocan.iarc.fr.

3. Plan Nacional de Prevención y Control de Cáncer de Cuello Uterino 2017 - 2021. Lima: Biblioteca Central del Ministerio de Salud; 2017. Disponible en http://bvs.minsa.gob.pe/local/MINSA/4232.pdf
4. Samperio Calderón J, Salazar Campos A. Eficacia de las pruebas diagnósticas del Cáncer Cervicouterino y Virus del Papiloma Humano. JONNPR 2019;4(5):551-566. DOI: 10.19230/jonnpr.2953 https://revistas.proeditio.com/ jonnpr/article/view/2953

5.Zambrano AraqueS, GónzalezBlanco M.Citología en baselíquida:parámetros de eficacia. Rev Obstet Venez.2015;75(3). Disponible en: http://ve.scielo.org/ scielo.php?script=sci_arttext\&pid=S0048-77322015000300007\&lang=es

6. Liu Y, Zhang L, Zhao G, Che L, Zhang H, Fang J. The clinical research of Thinprep Cytology Test (TCT) combined with HPV-DNA detection in screening cervical cancer. Cell Mol Biol (Noisy-le-grand). 2017;63(2):92. 10.14715/ $\mathrm{cmb} / 2017.63 .2 .14$ 